\title{
Analgesic and Anti-diarrhoeal Activities of Lagerstroemia speciosa Roots in Experimental Animal Model
}

\author{
Fahad Hussain ${ }^{1}$, Amlan Ganguly ${ }^{2}$, Mohammad Salim Hossain ${ }^{1}$ and \\ S.M. Abdur Rahman ${ }^{3}$
}

\author{
${ }^{1}$ Department of Pharmacy, Noakhali Science and Technology University, Noakhali, Bangladesh \\ ${ }^{2}$ Department of Pharmacy, Faculty of Life and Earth Science, Jagannath University, Dhaka-1100, Bangladesh \\ ${ }^{3}$ Department of Clinical Pharmacy and Pharmacology, Faculty of Pharmacy, University of Dhaka,
} Dhaka-1000, Bangladesh

Received: June 08, 2014; Accepted: June 23, 2014; Published (web): June 29, 2014

\begin{abstract}
The methanolic crude extract of Lagerstroemia speciosa roots was investigated for its possible analgesic and anti-diarrhoeal activities in experimental animal model. Phytochemical screening of the methanolic extract of $L$. speciosa roots showed the presence of alkaloids, flavonoids, saponins, tannins and reducing sugar. In acute toxicity study, no mortality or toxic reaction was recorded in animal model after administration of the $L$. speciosa roots extract. Analgesic activity was evaluated by using acetic acid induced writhing inhibition method in Swiss albino mice. In peripheral method of anti-nociception, the methanolic crude extract of $L$. speciosa roots showed significant analgesic activity. At the dose of 200 and $400 \mathrm{mg} / \mathrm{kg}$ body weight, the extract produced $35.38 \%$ and $53.85 \%$ ( $\mathrm{P}<0.001)$ of writhing inhibition, respectively compared to standard diclofenac sodium $(70.77 \%$ inhibition). The extract had also anti-diarrhoeal activity in castor oil induced method and inhibited the mean number of defecation by $32.75 \%(\mathrm{P}<0.01)$ and $51.72 \%(\mathrm{P}<0.001)$ at the dose of 200 and $400 \mathrm{mg} / \mathrm{kg}$ body weight, respectively. The latent period for the extract treated group also increased significantly.
\end{abstract}

Key words: Lagerstroemia speciosa, analgesic, writhing, anti-diarrhoeal, castor oil, Swiss albino mice

\section{INTRODUCTION}

Pain is an important symptom that brings the patient to physician. Analgesics relieve pain as a symptom, without affecting its cause. ${ }^{1}$ Diarrhoeal disease is a leading cause of mortality and morbidity, especially in children in developing countries. ${ }^{2}$ Majority of the people of developing countries rely on herbal drugs for the management of diarrhea. Considering the fact, the World Health Organization has constituted a diarrhoeal disease control programme, which includes studies of practices of traditional medicine, together with the elevation of health education and prevention approaches. ${ }^{2}$

Lagerstroemia speciosa (L.) Pers. (Bengali name: Jarul or Banaba; Family: Lythraceae) is a deciduous or semi-deciduous small to medium sized or rarely large tree up to $40-45$ meter tall. It is found

Correspondence to: S.M. Abdur Rahman

Tel: +88-02-9661920-73 (Ext-8166), Fax: +88-02-8615583

E-mail: rahman_du@yahoo.com

Dhaka Univ. J. Pharm. Sci. 13(1)1: 57-62, 2014 (June) all over the tropical and subtropical regions including Bangladesh, India, Malaysia, Thailand, Philippines, Indonesia and Japan. ${ }^{3}$ Traditionally the plant is called natural plant insulin due to its remarkable anti-diabetic effects without any noticeable side effect. ${ }^{3}$ Almost every part of the plant such as (bark, flower, fruit, leaf, root) has several important biological properties. Leaf decoction or infusion is used for bladder and kidney inflammation, dysuria and other urinary dysfunctions. ${ }^{4}$ Leaves are also used to make slimming tea and for cholesterol deduction, hypertension and diabetes. ${ }^{4}$ The bark part of the plant $L$. speciosa has local use for the treatment of diarrhea. ${ }^{4}$ Root of this plant has been used for a variety of stomach ailments. Some chemical constituents like gallic acid, 4-hydroxybenzoic acid, 3-O-methylprotocatechuic acid, caffeic acid, $p$ coumaric acid, kaempferol, quercetin, and isoquercitrin, have been isolated from $L$. speciosa roots. Six pentacyclic triterpene acids (oleanolic acid, 
arjunolic acid, asiatic acid, maslinic acid, corosolic acid and 23-hydroxyursolic acid) were isolated from L. speciosa leaves. ${ }^{5}$ The plant also contains flavonoids and saponins in a remarkable amount among other phytoconstituents which can act against pain and diarrhea. As the roots of the plant are widely available and only a limited study was conducted on roots of this plant, our present work was undertaken to validate the analgesic and anti-diarrhoeal potential of the methanolic crude extracts of $L$. speciosa using acetic acid- induced writhing inhibition and castor oil- induced diarrhea method, respectively in swiss albino mice for the first time.

\section{MATERIALS AND METHODS}

Collection and preparation of plant material. Fresh roots of the plant Lagerstroemia speciosa were collected from Kalia, Narail, Bangladesh in September, 2011. The roots of L. speciosa were identified and authenticated by taxonomist in the National Herbarium, Mirpur, Dhaka where a voucher specimen (accession no: 38212) has been deposited for future reference. Roots of L. speciosa were washed properly, cut into small pieces and then air dried for several days. The pieces were oven dried for 24 hours at considerably low temperature to facilitate grinding. The pieces were then ground into coarse powder by using a high capacity grinding machine.

Extraction of the plant material. About $700 \mathrm{~g}$ of the powdered material was taken in a clean, round bottomed flask (5 liters) and soaked in 2.5 liter of methanol. The container with its content was sealed with aluminium foil and kept for 7 days accompanying occasional shaking and stirring. The whole mixtures were then filtered through a fresh cotton plug and finally with a Whatman Number 1 filter paper. The volume of the filtrate was then reduced with a Büchi rotary evaporator at low temperature and pressure. The weight of the crude extract was $23 \mathrm{~g}$.

Drugs and reagents. Methanol, acetic acid, tween 80 (Sigma chemicals, USA), diclofenac sodium (ACI Pharmaceuticals Ltd, Dhaka), loperamide (Square Pharmaceuticals Ltd, Dhaka), normal saline (Opsonin Pharaceutical Ltd, Dhaka) were collected from the mentioned sources. Highly pure castor oil was collected from local market. All the chemicals and solvents were of analytical grade.

Experimental animals. Swiss albino mice (25$30 \mathrm{~g}$ ) of either sex, aged 4-5 weeks and Wistar rats $(125-150 \mathrm{~g})$ were obtained from Department of Pharmacy, Jahangirnagar University. They were housed in standard polypropylene cages and kept under controlled room temperature $\left(24 \pm 2^{\circ} \mathrm{C}\right.$; relative humidity $60-70 \%$ ) in a 12 hour light-dark cycle in the animal house of Institution of Nutrition and Food Science, University of Dhaka and fed with ICDDR,B formulated rodent food and water ad libitum. As these animals are very sensitive to environmental changes, they were kept before the test for 3-4 days in the environment where the experiment was conducted.

Phytochemical screening. The freshly prepared crude methanolic extracts of roots of $L$. speciosa were qualitatively tested for the presence of alkaloids, phenols, tannins, reducing sugar, flavonoids, steroids and saponins by using standard procedures. ${ }^{6,7}$

Acute toxicity test. The acute toxicity for methanolic extract of the roots of $L$. speciosa was determined in rats according to the method of Hilaly ${ }^{8}$ with slight modifications. Rats fasted for 16 hour were randomly divided into groups of five rats per group. Graded doses of the extract (200, 400, 800, 1600 and $3200 \mathrm{mg} / \mathrm{kg}$ p.o.) were separately administered to the rats in each of the group by means of bulbed steel needle. All rats were then allowed free access to food and water and observed over a period of 48 hour for signs of acute toxicity. The number of deaths within this period was recorded.

\section{Analgesic activity study}

Peripheral analgesic activity study. The peripheral analgesic activity of the crude methanolic extracts of $L$. speciosa was determined by the acetic acid- induced writhing inhibition method according to procedure described by Koster and Turner., ${ }^{9,10}$ 
Twenty Swiss albino mice were divided into four groups consisting of five animals in each. Each group received particular treatment as shown in Table 2. Then the response of the extract and diclofenac sodium treated groups was compared with those of the animals in the control group. Percentage inhibition of writhing in comparison to control group was taken as an index of analgesia and was calculated using the following formula:

Inhibition $(\%)=[(\mathrm{Wc}-\mathrm{Wt}) \times 100] / \mathrm{Wc}$

Where Wc is the average number of writhing reflex in the control group and Wt is the average number of writhing reflex in the test group.

Anti-diarrhoeal activity study. The method, described by Shoba and Thomas ${ }^{11}$ was followed for this study with slight modification. The animals were divided into control, positive control and test groups containing five mice in each group. Control group received vehicle (1\% Tween-80 in water) at $10 \mathrm{ml} / \mathrm{kg}$ b.w. orally. The positive control group received loperamide at the dose of $50 \mathrm{mg} / \mathrm{kg}$ b.w. orally; test groups received the methanol extract 200 and 400 $\mathrm{mg} / \mathrm{kg}$ b.w. Thirty minutes intervals were given to ensure proper absorption of the administered substances. Then $1 \mathrm{ml}$ of castor oil was administered to each mouse for inducing diarrhea. Each animal was placed in an individual cage, the floor of which was lined with blotting paper. Each of the mice was observed for four hours. The floor lining was changed every hour. Each time a mouse had given stool was recorded. The average of total number of stool given by the test group and the average of total number of stool given by the control group was compared. Percent inhibition of defecation in mice was calculated by using the following equation:

$\%$ inhibition $=\{(\mathrm{Mo}-\mathrm{M}) / \mathrm{Mo}\} \times 100 ;$ where, Mo $=$ Mean defecation of control and $\mathrm{M}=$ Mean defecation of test sample.

Statistical analysis. All values were expressed as the mean \pm standard error of the mean (SEM) and the results were analyzed statistically by one way analysis of variance (ANOVA) followed by Dunnett's ' $t$ '-test by using SPSS ver.19. $P<0.05$ was considered to be statistically significant.

\section{RESULTS AND DISCUSSION}

Phytochemical screening. Chemical group test results of the methanolic extract of $L$. speciosa roots showed the presence of alkaloids, flavonoids, tannins, saponins and reducing sugars (Table 1).

Acute toxicity test. In acute toxicity study, oral administration of graded doses (200, 400, 800, 1600 and $3200 \mathrm{mg} / \mathrm{kg}$, b.w., p.o.) of the methanol extract of $L$. speciosa to rats showed no significant changes in behavior, breathing, cutaneous effects, sensory nervous system responses or gastrointestinal effects during the observation period. No mortality or any toxic reaction was recorded in any group within 48 hour after administration. Thus $L$. speciosa was safe up to a dose level of $3200 \mathrm{mg} / \mathrm{kg}$ of body weight.

Table 1. Results of different chemical group tests of the methanolic extract of $L$. speciosa roots.

\begin{tabular}{ccccccc}
\hline $\begin{array}{c}\text { Plant } \\
\text { extract }\end{array}$ & Alkaloid & Reducing sugar & $\begin{array}{c}\text { Tannins (Phenolic } \\
\text { compounds }\end{array}$ & Flavonoids & Saponins & Glycoside \\
MCE & + & + & + & + & + & - \\
\hline
\end{tabular}

MCE: Methanolic crude extract of L. speciosa; +: positive result; - : negative result

Peripheral anti-nociceptive activity study. The peripheral anti-nociceptive effects of methanolic crude extract of the roots of $L$. speciosa in acetic acid- induced writhing inhibition method are shown in Table 2. The extracts effectively reduced the number of abdominal muscle contractions induced by
0.6\% acetic acid solution in a dose dependent manner. The methanolic crude extract at the dose of 200 and $400 \mathrm{mg} / \mathrm{kg}$ b.w. showed significant antinociceptive activity having $35.38 \%$ and $53.85 \%$ $(\mathrm{P}<0.001)$ of writhing inhibition, respectively compared to that exhibited by standard diclofenac (70.77\% inhibition). 
Anti-diarrheal activity study. The result of methanolic extract of $L$. speciosa roots on castor oilinduced diarrhea is shown in Table 3. Here, the methanolic extract at the dose of 200 and $400 \mathrm{mg} / \mathrm{kg}$ b.w. exhibited reduction of diarrhoeal feces by $32.75 \%$ and $51.72 \% \quad(\mathrm{P}<0.001)$, respectively compared to the reduction obtained by the standard drug loperamide (58.62\% feces reduction).
In this study, anti-nociceptive activity was evaluated peripherally by acetic acid-induced writhing inhibition method. This method is a simple and reliable method and is widely used to screen and study compounds for peripheral type analgesic action. ${ }^{12,13}$ In this experiment, the crude methanolic extract of $L$. speciosa roots significantly $(\mathrm{P}<0.001)$ lowered the number of writhing compared to standard diclofenac sodium.

Table 2. Peripheral anti-nociceptive activity of methanolic crude extract of $L$. speciosa roots.

\begin{tabular}{cccccccc}
\hline $\begin{array}{c}\text { Animal } \\
\text { Group }\end{array}$ & \multicolumn{3}{c}{ Writhing count } & & $\begin{array}{c}\text { Number of writhing } \\
\text { (Mean } \pm \text { SEM) }\end{array}$ & $\begin{array}{c}\% \text { of Inhibition of } \\
\text { writhing }\end{array}$ \\
\cline { 2 - 6 } & $\mathrm{M}_{1}$ & $\mathrm{M}_{2}$ & $\mathrm{M}_{3}$ & $\mathrm{M}_{4}$ & $\mathrm{M}_{5}$ & & - \\
$\mathrm{NC}$ & 27 & 25 & 28 & 24 & 26 & $26 \pm 0.7$ & $70.77 * * *$ \\
$\mathrm{PC}_{50}$ & 7 & 8 & 7 & 10 & 6 & $7.6 \pm 0.67$ & $35.38 * * *$ \\
$\mathrm{MCE}_{200}$ & 17 & 19 & 17 & 15 & 16 & $16.8 \pm 0.66$ & $53.85 * * *$ \\
$\mathrm{MCE}_{400}$ & 14 & 12 & 10 & 13 & 11 & $12 \pm 0.70$ & 5 \\
\hline
\end{tabular}

Values expressed as Mean $\pm \mathrm{SEM}(\mathrm{n}=5)$. *** $\mathrm{P}<.001, * * \mathrm{P}<.01, * \mathrm{P}<.05$ significant compared to control. $\mathrm{NC}=$ negative control, $\mathrm{PC}$ $=$ positive control (Diclofenac sodium), $\mathrm{MCE}_{200}=$ Methanolic crude extract of $L$. speciosa roots at $200 \mathrm{mg} / \mathrm{kg}$ body weight, $\mathrm{MCE}_{400}$ $=$ Methanolic crude extract of $L$. speciosa roots at $400 \mathrm{mg} / \mathrm{kg}$ body weight. $\mathrm{M}_{1}, \mathrm{M}_{2}, \mathrm{M}_{3}, \mathrm{M}_{4}$ and $\mathrm{M}_{5}=\mathrm{Mice}_{1}$, Mice 2, Mice 3, Mice 4 and Mice 5.

Table 3. Effect of methanol extract of $L$. speciosa roots on castor oil $(1 \mathrm{ml} / \mathrm{mice})$ induced diarrhea in mice.

\begin{tabular}{lccc}
\hline \multicolumn{1}{c}{ Treatment } & Dose & $\begin{array}{c}\text { Number of diarrheal feces } \\
(\text { Mean } \pm \text { SEM) }\end{array}$ & \% Reduction of diarrhea \\
\hline Control (Saline) & $10 \mathrm{ml} / \mathrm{kg} \mathrm{b.w.}$ & $11.6 \pm 0.50$ & $\cdots$ \\
Standard (Loperamide) & $50 \mathrm{mg} / \mathrm{kg} \mathrm{b.w.}$ & $4.8 \pm 0.37$ & $58.62^{* * *}$ \\
$\mathrm{MCE}_{200}$ & $200 \mathrm{mg} / \mathrm{kg} \mathrm{b.w.}$ & $7.8 \pm 0.58$ & $32.75^{* *}$ \\
$\mathrm{MCE}_{400}$ & $400 \mathrm{mg} / \mathrm{kg} \mathrm{b.w.}$ & $5.6 \pm 0.50$ & $51.72^{* * *}$ \\
\hline
\end{tabular}

Values are expressed as Mean \pm SEM $(\mathrm{n}=5)$. *** $\mathrm{P}<0.001, * * \mathrm{P}<0.01, * \mathrm{P}<0.05$ compared to control (One way ANOVA followed by Dunnett's test). Standard $=$ (Loperamide) $50 \mathrm{mg} / \mathrm{kg}, \mathrm{MCE}_{200}=$ Methanolic crude extract of $L$. speciosa roots at $200 \mathrm{mg} / \mathrm{kg}$ body weight, $\mathrm{MCE}_{400}=$ Methanolic crude extract of $L$. speciosa roots at $400 \mathrm{mg} / \mathrm{kg}$ body weight.

In evaluation of anti-diarrhoeal activity by castor oil method, methanolic crude extract dosedependently reduced diarrhoeal feces which was comparable to that obtained by the standard loperamide. Castor oil causes diarrhea due to its active metabolite, ricinolic acid, which stimulates peristaltic activity in the small intestine, leading to changes in electrolyte permeability of the intestinal mucosa. ${ }^{14,15}$ The liberated ricinoleic acid also causes irritation and inflammation of the intestinal mucosa leading to the release of endogenous prostaglandins. ${ }^{16}$ Several other mechanism have been reported to cause diarrhea by castor oil inducing inhibition of intestinal $\mathrm{Na}^{+} / \mathrm{K}^{+}$-ATPase activity, activation of adenylate cyclase or mucosal cAMP- mediated active secretion and platelet activating factor. ${ }^{17}$ Diarrhea also results from an active intestinal secretion driven predominantly by net secretion of sodium and potassium. Therefore, the decrease in the wetness of feces and the frequency of defecation observed with the extract prove the potent anti-diarrhoeal activity of $L$. speciosa roots and this effect might be due to inhibition of prostaglandins biosynthesis.

The analgesic and anti-diarrheal activities of many plants have been attributed to their saponin, ${ }^{18}$ terpenoids, flavonoids and steroids contents. ${ }^{19}$ Moreover, the flavoloids, triterpenoids are known to inhibit prostaglandin systhesis. ${ }^{20}$ The phytochemical investigation revealed that $L$. speciosa possessed the maximum phytochemicals like alkaloids, flavonoids, 
saponins, reducing sugars, tannins and phenolic compounds. It is not unreasonable, therefore to speculate that the flavonoids, saponins, tannins present in the plant extract may be responsible for the observed analgesic and anti-diarrhoeal effects.

\section{CONCLUSION}

In conclusion, the overall results of the present study indicate the analgesic and anti-diarrhoeal activities of the roots of $L$. speciosa which deserves further investigation to isolate the active constituents responsible for these activities and to establish the mechanisms of action. The results of the present study provided a scientific support for the use of $L$. speciosa in the treatment of pain and diarrhea related disorders in ethnomedicine.

Declaration of interest. The authors declare no conflict of interest.

\section{ACKNOWLEDGEMENTS}

The authors are grateful to the Department of Clinical Pharmacy and Pharmacology, Faculty of Pharmacy, University of Dhaka, Bangladesh, for providing laboratory facilities. We would also like to express our gratitude to the authority of Jahangirnagar University, Dhaka, Bangladesh and International Centre for Diarrhoeal Disease and Research, Bangladesh (ICDDR, B) for providing the experimental animals and fed for experimental animals respectively. Fahad Hussain thanks Ministry of Science, Information and Communication Technology, Govt. of Bangladesh for a fellowship (NST/Fellow/2012-2013/Life Science and Medical Sciences/168) as a financial aid to this research work.

\section{REFERENCES}

1. Mate, G.S., Naikwade, N.S., Chowki, C.S. and Patil, S.B. 2008. Evaluation of anti-nociceptive activity of Cissus quadrangularis on albino mice. Int. J. Green Pharm. 2, 118121.

2. Das, A.K., Mandal, S.C., Banerjee, S.K., Sinha, S., Das, J., Saha, B.P. and Pal, M. 1999. Studies of anti-diarrheal activity of Punica granatum seed extracts. J. Ethnopharmacol. 68, 205-208.
3. Takano, J. 2013. Lagerstroemia Speciosa L. (Banaba or Queen's Flower) - Wonders of Botanical Herbs: Pyroenergen. Available from: http://www.pyroenergen.com/otherproducts/banaba-plant.htm.

4. Wei, D. 2013. Philippine Medicinal Plants - Banaba: Stuart Xchange. Available from: http://www.stuartxchange. com/Banaba.html.

5. Hou, W., Li, Y., Zhang, Q., Wei, X., Peng, A. and Chen, L. 2009. Triterpene acids isolated from Lagerstroemia speciosa leaves as $\alpha$-glucosidase inhibitors. Phytother. Res. 23, 614618.

6. Ghani, A. 2003. Medicinal plants of Bangladesh with Chemical Constituents and Uses, Asiatic Society of Bangladesh, Dhaka, Bangladesh.

7. Trease, G.E., Evans, W.C. 1989. A Text Book of Pharmacognosy. 13th ed. Cambridge University Press, London.

8. Hilaly, J.E., Israili, Z.H. and Lyoussi, B. 2004. Acute and chronic toxicological studies of Ajuga iva in experimental animals. J. Ethnopharmacol. 91, 43 -50.

9. Koster, R., Anderson, M. and De Beer, E.J. 1959. Acetic acid for analgesic screening. Proceedings of the Society for Experimental Biology and Medicine 18, 412-415.

10. Turner, R.A. 1971. Screening Methods in Pharmacology. Academic Press: New York; P.100-110.

11. Shoba, F.G. and Thomas, M. 2001. Study of anti-diarrheal activity of four medicinal plants in castor oil induced diarrhea. J. Ethnopharmacol. 76, 73-76.

12. Collier, H.O., Dinneen, L.C., Johnson, C.A. and Schneider, C. 1968. The abdominal constriction response and its suppression by analgesic drugs in the mouse. Br. J. Pharmacol. 32, 295-310.

13. Singh, S. and Majumder, D.K. 1995. Analgesic activity of Ocimum sanctum and its possible mechanism of action. Int. J. Pharmacognosy 33,188-192.

14. Ammon, H.V., Thomas, P.L. and Phillips, S.F. 1974. Effects of oleic and ricinoleic acids on net jejunal water and electrolyte movement. Perfusion studies in man. J. Clin. Invest. 53, 374-379

15. Tanko, Y., Alladey, O., Ahmed, M.K., Mohammed, A. and Musa, K.Y. 2012. The effect of methanol leaves extract of Ficus glumosa on gastrointestinal motility and on castor oil induced diarrhea in laboratory animals. J. Nat. Prod. Plant. Resour. 2, 360-367.

16. Galvez, J., Zarzuelo, A., Crespo, M.E., Lorente, M.D., Ocete, M.A. and Jimenez J. 1993. Anti-diarrhoeic activity of Euphorbia hirta extract and isolation of an active flavonoid constituent. Planta Med. 59, 333-336.

17. Meite, S., N'guessan, J.D., Bahi, C., Yapi, H.F., Djaman, A.J. and Guina, F.G. 2009. Anti-diarrheal activity of the ethyl acetate extract of Morinda morindoides in rats. Trop. J. Pharm. Res. 8, 201-207. 
18. Oweyele, V.B., Oloriegbe, Y.Y., Balogun, E.A. and Soladoye, A.O. 2005. Analgesic and anti-inflammatory properties of Nelsonia canescens leaf extract. J. Ethnopharmacol. 99, 153-56.

19. Adeolu, A.A., Margaret, O.S., Viola, M., Moyo, B., Masika, P.J. and Afolayan, A.J. 2008. Anti-inflammatory and analgesic activities of the aqueous extract of Cussonia paniculata stem bark. Rec. Nat. Prod. 2, 46-53.
20. Mohammad, S., Naghmeh, H. and Mohammad, K. 2004. Analgesic and anti-inflammatory activity of Lactuca sativa seed extract in rats. J. Ethnopharmacol. 92, 325-329. 